\section{Combining Categories of Management Control Tools for High Performance of Start-ups}

\author{
Wendy Beatriz Witt Haddad Carraro' 1 \\ ${ }^{1}$ Federal University of Rio Grande do Sul, Faculty of Economics, Post-Graduation \\ Program in Controllership and Accounting, Porto Alegre, Brazil \\ Raquel Meneses ${ }^{2}$ \\ Carlos Brito ${ }^{2}$ \\ ${ }^{2}$ University of Porto, Faculty of Economics, Management, Porto, Portugal
}

Received on

04/25/2018

Approved on

$02 / 14 / 2019$

\section{Responsible editor:}

Prof. Dr. João Maurício Gama

Boaventura

Evaluation process:

Double Blind Review

\begin{abstract}
Purpose - This study aims is to examine possible combinations of management control tools that are likely to lead to high performance in start-ups.

Design/methodology/approach - Personal interviews were conducted with entrepreneurs from 45 start-ups established in Technology Parks of University Centers in Portugal. Based on practices from different categories of organizational analysis, it was used the fuzzy Qualitative Comparative Analysis (fsQCA) methodology.

Findings - To achieve high performance, management controls are required for Clients, Strategy, Information Systems, Performance, Risks and Budget. The Client and Budget categories presented the greatest consistency in meeting the proposed condition. In addition, the results generated two combinations of conditions for the high performance of net income.
\end{abstract}

Originality/value - The combination of different management control practices contributes to the success of the business, especially when it relates to the organization's strategic practices. The use of management control tools becomes a priority for companies that wish to cope with the challenges raised by corporate uncertainties, especially in start-up companies, ensuring the sustainable growth of these businesses.

Keywords - Management control, start-ups, performance, practices.

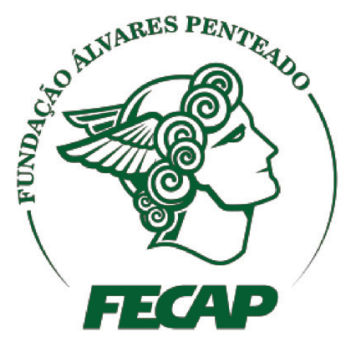

Review of Business Management

DOI: $10.7819 /$ rbgn.v21i5.4022 


\section{Introduction}

According to Ries (2011), start-ups do not exist to "do things" - rather, they are created to build a sustainable innovative business. Blank and Dorf (2012, p. 17) offer a definition of start-up: "a temporary organization in search of a scalable, repeatable, profitable business model.” Workers of small firms are in close contact with an entrepreneurial role model and are likely to acquire entrepreneurial skills more easily than workers of large firms. Such role model effects may trigger a positive perception of entrepreneurship and stimulate a personal decision to start a firm (Battisti, 2019; Fritsch \& Wyrwich, 2018).

Start-ups often fail because founders and investors neglect to look before they move forward, without taking the time to realize that the basic business plan assumption is wrong. Entrepreneurs tend to be single-minded with their strategies, wanting the venture to be all about the technology or all about the sales, without taking time to form a balanced plan. According to Nobel (2011), sixty percent of start-ups do not survive the first five years, whilst seventy-five percent of venture capital funded start-ups fail. Moreover, most empirical studies referring to management control systems in new ventures or small and medium-sized firms have focused on the context of developed countries (Lin, Chen, \& Lin, 2017).

From the moment of their establishment, the focus of these companies is the development and penetration of their products in the market, based on a strong presence of technology and innovation in their production process. Among the most common problems that threaten the survival of these companies is the absence of management tools and procedures (Magdaleno, Engiel, Tavares, Pisa, \& Araujo, 2017).

Management control tools are instruments designed to induce individuals to behave in a manner that is consistent with the organization's objectives and strategies. According to Alvesson and Kärreman (2004), management control is necessary to develop an effective organization of work. Addressing management controls in startups is important. However, they should be used once there is a routine (Abernethy \& Brownell, 1997). Thus, the stage of the life cycle in which the firm finds itself should be borne in mind when this approach is addressed (Wang, Edison, Bajwa, Giardino, \& Abrahamsson, 2016).

In addition, management control systems are time-consuming and expensive (Sandelin, 2008). This means that each company may have both formal and informal control mechanisms tailored to its needs and resources. Having management control tools becomes a top priority for companies that wish to overcome the challenges raised by business uncertainties.

This issue has been investigated by researchers over the past two decades (cf. Abernethy \& Brownell, 1997; Davila \& Foster, 2005; Otley, 1999; Sandelin, 2008; Sandino, 2007). Nevertheless, more recently, a number of relevant studies have sought to analyze the practices of management control tools in start-ups (Bolisani \& Bratianu 2017; Busco, Giovannoni, \& Riccaboni, 2017; Elbashir, Collier, \& Sutton, 2011; Ferreira \& Otley, 2009; Magdaleno et al., 2017; Manyaeva, Piskunov, \& Fomin, 2016; Strauß \& Zecher, 2013; Voss \& Brettel, 2014).

In this context, the objective of this paper is to examine possible combinations of management control tools that are likely to lead to high performance in start-ups. The study involves the development of a new methodology on the basis of a conceptual framework that led to the identification of nine categories of analysis: Clients, Strategy, Information Systems, Quality, Performance, Collaborators, Risks, Budget, and Costs.

To develop the research, we interviewed forty-five entrepreneurs whose start-ups are based in science and technology parks linked to universities. The interviews were conducted face-to-face, allowing for the identification of management control tools and practices for each category of analysis. The fuzzy-set qualitative comparative analysis (fsQCA) methodological 
approach was used, which is an analytical technique that uses Boolean algebra to implement principles of comparison involving qualitative studies of social phenomena (Rihoux \& Ragin, 2008).

Recent studies have examined combinations of management control tools in different strategic contexts in large organizations using the fsQCA methodology (Bedford, Malmi, \& Sandelin, 2016; Erkens \& Van der Stede, 2015). The intention to study the combination of practices in start-ups is justified since they need a set of tools that allow them to achieve good enough performance for them to thrive.

Knowledge is a key source of competitive advantage for start-ups, particularly in innovative industries (Acs, Brooksbank, Gorman, Pickernell, \& Terjesen, 2012; Fritsch \& Aamoucke, 2013; Fritsch \& Wyrwich, 2018). Accordingly, new ventures can be regarded as expressions of knowledge spillovers from existing knowledge sources (Fritsch \& Wyrwich, 2018). As a consequence, this study contributes to management control literature in several ways. Firstly, the study provides evidence on how management control tools enhance the performance of start-ups. Secondly, it shows that management controls related to Clients, Strategy, Information Systems, Performance, Risks, and Budgets are interconnected and are necessary to achieve sustainable results, expanding knowledge applied to large companies (cf. Bedford et al., 2016; Erkens \& Van der Stede, 2015). Thirdly, the methodological approach used makes it possible to offer insights on the organizational

The paper is structured into five sections. After this introduction, the second section addresses the literature review on management control tools. This is followed by a section that focuses on the methodology and then there is a section on the results which discusses its implications. Finally, the key contributions of the study both to researchers and practitioners are summarized in the conclusion, along with the limitations of the investigation and suggestions for further research.

\section{Conceptual Background}

According to Ries (2011), start-ups are new human institutions which create new products or services under a high level of uncertainty. Thus, start-ups are considered to be open, flexible, creative, and innovative systems (Kalliath, Bluedorn, \& Gillespie, 1999). However, this kind of freedom can also be a weakness. Bruneel, Ratinho, Clarysse, and Groen (2012) stress that the lack of management experience and marketing skills of start-ups tends to be the main cause for their short life cycle and high death rate. In this regard start-ups face a trade-off: they need flexibility to be creative and innovative, but, at the same time, they also need management controls to survive.

Anthony (1965) was the first author to present a formalization of the management control concept. In his seminal work, the author refers to it as the process through which managers ensure that resources are obtained and used effectively and efficiently to achieve organizational objectives. Elements of management control systems include strategic planning, budgeting, resource allocation, performance measurement, evaluation and reward, allocation of responsibility centers, and transfer pricing (Anthony \& Govindarajan, 1998). Moreover, Atkinson, Kaplan, Matsumura, and Young, (2011, p. 275) state that "control refers to the set of procedures, tools, performance measures, systems, and incentives that organizations use to guide and motivate all employees to achieve organizational goals."

In short, management control is the process by which managers at all levels ensure that the people they lead will implement their intended strategies. The literature presents different perspectives on management control concepts, models, and practices. In this overview, a compilation of management control tools comprising different perspectives and pervading the entire organization will be provided. There is a strong relationship between strategic guidelines 
and company performance. Product innovation can significantly assist a competitor-led company to improve its financial performance, while a technology-driven company improves its growth and performance in the marketplace (Trapp, Voigt, \& Brem, 2017).

This theoretical analysis, based on studies that focus on performance and business management, shows the importance of developing a holistic tool aimed at assessing the extent to which the organization can control in a comprehensive way all aspects related to the nine categories of analysis: Clients, Strategy, Information Systems, Quality, Performance, Collaborators, Risks, Budget, and Costs. This evaluation examines instruments and practices that are considered in management control.

The category of analysis related to Clients includes instruments and practices that aim to control the management of relationships with both current and potential customers. In contrast to the approach assumed by large companies, both startups and SMEs have stated that customer needs are the primary motive for seeking partners. For this, start-ups and SMEs can combine know-how, core competences, and complementary resources (Mercandetti, Larbig, Tuozzo, \& Steiner 2017). Examples of customer management practices include databases, customer satisfaction surveys, and studies on customer loyalty (Atkinson et al., 2011; Busco et al., 2017; Magdaleno et al., 2017; Sandelin, 2008; Sandino, 2007). The organization's internal and external control mechanisms, when based on the market, can be employed to align the interests of managers and other stakeholders. An example is professional digital marketing, which builds social bonds with customers while recognizing them as clients and not merely nameless faces.

The category related to Strategy encompasses practices that aim to dynamically and systemically achieve strategic objectives. In this context, examples of strategy management controls include the definition of the mission, vision, and purpose of the business or strategic planning models (Alvesson \& Kärreman, 2004; Anthony \& Govindarajan, 1998; Atkinson et al., 2011; Bedford et al., 2016; Bolisani \& Bratianu, 2017; Elbashir et al., 2011; Erkens \& Van der Stede, 2015; Ferreira \& Otley, 2009; Magdaleno et al., 2017; Manyaeva et al., 2016; Otley, 1999; Sandino, 2007; Voss \& Brettel, 2014).

The category of management control analysis linked to Information Systems aims to verify to what extent the organization is organized with regard to its information management. These controls should be in charge of both internal and external mechanisms. Having a management information system, whether integrated or not, is an example of management control in this category (Atkinson et al., 2011; Bolisani \& Bratianu, 2017; Davila \& Foster, 2005; Elbashir et al., 2011; Magdaleno et al., 2017; Manyaeva et al., 2016; Miranda, 2011; Otley, 1999; Sandino, 2007).

The Quality category includes management controls and practices related to organizational processes as well as business productivity measures. Quality systems are the most common example of practices in this category of analysis (Alvesson \& Kärreman, 2004; Atkinson et al., 2011; Bolisani \& Bratianu, 2017; Busco et al., 2017; Elbashir et al., 2011; Magdaleno et al., 2017; Manyaeva et al., 2016; Miranda, 2011; Otley, 1999; Sandelin, 2008; Sandino, 2007)

The Performance category includes measures that aim to group business performance indicators, whether financial or non-financial. In this category, some instruments enable objective monitoring of whether targets are being met or not. Performance results of the business subsystem also reflect organizational effectiveness (Wang \& Ahmed, 2010). Viability indicators and balanced scorecards are good examples of this category of analysis (Abernethy \& Brownell, 1997; Alvesson \& Kärreman, 2004; Anthony \& Govindarajan, 1998; Atkinson et al., 2011; Bedford et al., 2016; Bolisani \& Bratianu, 2017; Davila \& Foster, 2005; Elbashir et al., 2011; Erkens \& Van der Stede, 2015; Ferreira \& Otley, 
2009; Magdaleno et al., 2017; Manyaeva et al., 2016; Miranda, 2011; Otley, 1999; Sandelin, 2008; Sandino, 2007)behavior and personnel controls","container-title":"Accounting, Organizations and Society","page":"233-248","vo lume":"22","issue":"3","source":"ScienceDirect ", "abstract":"This paper reports the result of an empirical study examining the role of accounting and non-accounting controls in a research and development setting. The paper draws on Perrow's model of technology and structure to explore the influence of task characteristics on the effectiveness of accounting, behavior and personnel forms of control (Perrow, 1970.

Management control practices and instruments related to Collaborators are those aimed at aligning the organizational objectives with those who work in the company. It is essential that there should be harmony between these objectives. The instruments in this category of analysis should reinforce this control and alignment. The most common controlling practices in this category of analysis are performance appraisal and profit distribution (Abernethy \& Brownell, 1997; Atkinson et al., 2011; Bolisani \& Bratianu, 2017; Busco et al., 2017; Davila \& Foster, 2005; Magdaleno et al., 2017; Otley, 1999; Sandelin, 2008; Sandino, 2007; Voss \& Brettel, 2014). Trust is an important construct in business operations, which incorporates key elements such as honesty, integrity, and individual motivations. These can be reinforced through a dyadic employer-employee relationship (Wang, 2016). Employees should feel they benefit from the actions of their employer. The tendency of individuals to avoid misreporting depends not only on the management control system design but also on the match between it and the individual's cognitive orientations (Sánchez-Expósito \& Naranjo-Gil, 2017).

Risks for a business operation deserve specific attention since they correspond to the controls and mechanisms that promote risk mitigation. To use this, it is recommended that companies identify and assess the degree of impact and likelihood of risk occurrence. In this way it is possible to act based on the most significant probability and impact on the business, avoiding financial waste. Examples in this category are internal audits, business codes of conduct, and internal operational control practices (Alvesson \& Kärreman, 2004; Atkinson et al., 2011; Bolisani \& Bratianu, 2017; Busco et al., 2017; Davila \& Foster, 2005; Elbashir et al., 2011; Magdaleno et al., 2017; Miranda, 2011; Sandelin, 2008; Sandino, 2007).

The Budget includes the instruments related to cash flow, operating budget, and financing. Companies that have external investors usually need to present and prepare budgets monthly or annually. Accountability is based on these budget instruments (Anthony \& Govindarajan, 1998; Atkinson et al., 2011; Davila \& Foster, 2005; Magdaleno et al., 2017; Manyaeva et al., 2016; Miranda, 2011; Sandelin, 2008; Sandino, 2007).

In management control, the tool that is used for Costs analysis is the product or the service. Break-even analysis, costing for sales price formation, and cost analysis are very common examples of practices in this category of analysis (Anthony \& Govindarajan, 1998; Atkinson et al., 2011; Davila \& Foster, 2005; Manyaeva et al., 2016; Miranda, 2011; Sandelin, 2008; Sandino, 2007). Cost management is fundamental when seeking to apply a cost leadership strategy. Managing production costs is a variable strategy especially in countries with high costs (Chen, Eriksson \& Giustiniano, 2017; Rosenthal, 2004).

Using the theoretical reference enabled a set of more than 140 practices to be identified, distributed within the nine categories addressed before (Carraro, Battisti \& Brito, 2019). In addition to the practices and instruments of management control, characteristics such as company size, sector of activity, and management model are factors that may influence the decision to use management control practices and instruments (Anthony \& Govindarajan, 1998; Atkinson et al., 2011; Bedford et al., 2016; Davila 
\& Foster, 2007; Ferreira \& Otley, 2009; Malmi \& Brown, 2008).

To sum up, the management control tools pointed out in the literature support the further development of the research. In fact, they are the basis for the questionnaire developed to identify the practices followed by the start-ups. The methodological aspects related to this process are described in the next section.

\section{Methodology}

Based on the literature review conducted in the previous section, we developed an instrument for the collection of data from the sample of start-ups established in science and technology parks linked to universities. This section discusses the methodological approach in terms of data collection and data analysis.

\section{I Data collection}

Data were collected through a questionnaire (Appendix A) based on the elements consulted in the literature that enabled the identification of nine categories of analysis of management controls as well as the necessary features of the business. We conducted a pre-test of the questionnaire with a group of entrepreneurs and teams responsible for management and support given to start-up companies from technology parks. The interviews were carried out in person and recorded, with an average time of 23 minutes.

To examine possible combinations of categories of management control tools leading to high performance in start-ups, we conducted personal interviews with 45 entrepreneurs from start-ups established in science and technology parks in three universities in the north of Portugal, a region that is particularly dynamic in terms of entrepreneurship. $64 \%$ of the interviewees were company partners, $25 \%$ were CEOs, and $11 \%$ were CFOs and CMOs.

In terms of area of activity, $70.7 \%$ were tech-based companies while $29.3 \%$ were startups working in the creative industry. Regarding the age of the company, most of the companies were less than 3 years old ( $41.5 \%)$, followed by companies with 3 to 5 years in operation (29.3\%), and $12.2 \%$ that were set up less than one year before.

On average, these companies had seven employees. However, when analyzing this data by thematic group, it can be observed that the average is higher for tech-based companies, with nine employees, whereas the creative industry companies had on average four employees. Finally, $73.2 \%$ of the start-ups were already operating in the market. Others had some more specific characteristics, whether in the process of certification, execution for delivery, Minimum Viable Product (MVP) development, beginning commercialization, in testing, or in a beta phase.

Regarding funding for their planned investments, $71 \%$ of the companies reported that this came from external investors or partners' equity. Concerning the question of the product phase, it is to be expected that companies that were not yet present in the market were not yet billing.

$46.3 \%$ of the companies were in the billing category of $\leq 100$ thousand euros, $29.3 \%$ had an income of $<=500$ thousand euros, $2.4 \%$ earned $<=2$ million euros, and $2.4 \%<=$ 10 million euros. The pre-billing companies represented $19.5 \%$ of the participants, and 59\% presented a decentralized management model. We observed that the companies that worked in the technological area counted on greater support from internal employees for the management of the company.

The participants were asked about the importance of category controls, considering a scale of $0=$ Not Important $/ 1=$ Of Small Importance / 2 = Of Medium Importance / 3 = Very Important $/ 4=$ Absolutely Essential. They indicated a higher score for management controls related to Clients (with an average of 3.9), followed by Strategy and Employees (both with an average of 3.5). The Performance (3.4) and Quality (3.3) categories also obtained a significant score. However, the Costs (3.0), Risks 
(3.0), Budget (2.9), and Information Systems (2.7) categories presented a lower score.

\subsection{Data analysis}

Based on the data collected, referring to the management control practices and instruments used by the start-ups included in the sample, a qualitative-comparative analysis was carried out in greater depth, using fuzzy-set qualitative comparative analysis (fsQCA). This methodology is a powerful analytical technique that uses Boolean algebra to implement principles of comparison in studies (Ragin, 1987). The method favors dialogue between empirical evidence and hypotheses, allowing the results to support the analysis. It is appropriate to test for possible configurations of causal factors (conditions) that explain, or do not explain, a given result (Fiss, 2011; Ragin, 2008). The method was considered as a way of performing comparative analyses, seeking associations between specific conditions and results. It enables the systematization and operationalization of conditions or configurations, allowing for cross-case analysis of a particular phenomenon under analysis (Rihoux \& Meur, 2009). In this sense, fsQCA is particularly useful to understand the complementarities and the substitutes for configurations (Fiss, 2011).

The test with this analytical methodology is to identify how the combination of management controls leads to high start-up performance. Therefore, it is necessary to relate the degree of performance with the variables collected. fsQCA software version 3.0 was used for this analysis.

This model deals with two important concepts: consistency and coverage. The behavior of the variables was assessed using these two indicators. Consistency represents the proportion of cases in which a given cause or combination generates a result. Coverage indicates the total number of cases following a specific path for the result divided by the total number of instances of the result (Ragin, 1987).
An essential step in fsQCA is the construction of a truth table, in which an algorithm based on Boolean algebra is used to logically reduce lines to simplified combinations. This study uses the truth table algorithm described by Ragin (2008) and Rihoux and Ragin (2008), based on a factual analysis of causal conditions, which has the advantage of enabling a categorization of the resulting conditions.

This method was used particularly to identify which categories of management control should be considered in order to achieve high net profit performance, as well as other conditions identified in the study. The sequence to be considered for analysis utilizing fsQCA is:

a) codification of the conditions with an interval between 1 and 0 , with 1 being the best assessment, according to Table 1;

b) selection of the variables to be analyzed in the fsQCA software;

c) identification of the conditions needed to attend to the established issue; and

d) construction of the truth table for simplified combinations of the necessary conditions.

In each of the conditions, several tools could be used. Thus, it was necessary to use Boolean algebra to combine the various tools. According to Ragin (2008), two or more fuzzy sets can be integrated with the logical operation 'or' or 'and'. In this case, 'or' was used, which means that it was enough to have used one of the possible tools.

After coding, the selection of these variables was undertaken to analyze the necessary conditions for high net profit performance in the fsQCA software. To identify the extent to which the variables were relevant to net income performance, this should be considered in the 'outcome' field. The other variables must be considered as the 'conditions'. 
Table 1

Variables Coding for fsQCA Analysis

\begin{tabular}{|c|c|}
\hline Variables & Coding fsQCA \\
\hline Area of Expertise & $\begin{array}{l}\text { Technological / Bio / Sea: } 1 \\
\text { Creative: } 0\end{array}$ \\
\hline Stage of the product / service & $\begin{array}{l}\text { In the Market: } 1 \\
\text { E Beta Development: } 0 \\
\text { Company Credits } \\
\text { Mvp Starting Trading: } 0.5 \\
\text { Running For Delivery: } 0.5\end{array}$ \\
\hline Funding for the planned investment & $\begin{array}{l}\text { Yes } 1 \\
\text { No: } 0\end{array}$ \\
\hline Billing & $\begin{array}{l}\text { With Billing: } 1 \\
\text { No Billing: } 0\end{array}$ \\
\hline Management model & $\begin{array}{l}\text { Decentralized: } 1 \\
\text { Centralized: } 0 \\
\text { Mixed: } 0.5\end{array}$ \\
\hline Management support & $\begin{array}{l}\text { There is some: } 1 \\
\text { Does not have: } 0\end{array}$ \\
\hline $\begin{array}{l}\text { Practices in each category of analysis (Clients, Strategy, } \\
\text { Information Systems, Quality, Performance, Employees, } \\
\text { Risks, Budget, and Costs) }\end{array}$ & $\begin{array}{l}\text { Practice totally used in the company: } 1 \\
\text { Practice partially used in the company: } 0.8 \\
\text { Practice used in the company: } 0.6 \\
\text { Practice was used, but has been discontinued: } 0.4 \\
\text { Attempt to implement the practice without success: } 0.2 \\
\text { Practice has never been used in the company: } 0\end{array}$ \\
\hline Net Income Performance & $\begin{array}{l}\text { Very high: } 1 \\
\text { High: } 0.8 \\
\text { Medium } 3: 0.6 \\
\text { Low: } 0.4 \\
\text { Not measured: } 0.2 \\
\text { Does not have: } 0\end{array}$ \\
\hline
\end{tabular}

\section{Discussion of Results}

\section{I High performance}

After running the conditions described in Table 1, it is possible to identify which ones are necessary for high performance. The results are summarized in Table 2. To interpret this, we must consider that this methodology highlights the consistency of the condition tested. In order to have consistency for the condition tested with the necessary criterion for the degree of contribution, the index should represent a value higher than 0.90 (Schneider \& Wagemann, 2010). In the illustration, the conditions within this specification are highlighted. 
Table 2

\section{Result of fsQCA Analysis for Net Income Performance Outcome}

\begin{tabular}{lcc}
\hline Tested conditions & Consistency & Coverage \\
\hline Area of Expertise & 0.72449 & 0.43030 \\
Stage of the product / service & 0.90816 & 0.47467 \\
Funding for the planned investment & 0.67347 & 0.41250 \\
Billing & 1.00000 & 0.52973 \\
Management model & 0.45918 & 0.34615 \\
Management support & 0.85714 & 0.43077 \\
Clients & 0.98980 & 0.47087 \\
Strategy & 0.90816 & 0.50000 \\
Information Systems & 0.93878 & 0.46465 \\
Quality & 0.88776 & 0.49153 \\
Performance & 0.95918 & 0.50811 \\
Employees & 0.73469 & 0.48322 \\
Risks & 0.95918 & 0.47475 \\
Budget & 0.98980 & 0.48500 \\
Costs & 0.85714 & 0.46667 \\
\hline
\end{tabular}

The results show that to achieve high performance in the company's net profit (considered as medium, high, or very high), the start-up must have billing and the product or service must already be in the market. It should be noted that for a good result management control, tools or practices were needed in the following categories of analysis: Clients, Strategy, Information Systems, Performance, Risks, and Budget. The Clients and Budget categories were the ones that presented the highest consistency: 98.98\% to meet the proposed condition. These conditions are general conditions since they are present in all cases but one.

It was also noted that the 'Area of Expertise' (start-up's thematic hub), the 'Funding for Planned the Investment', the 'Management Model' of the company, whether centralized or decentralized, and having 'Management Support' are not conditions. To achieve a high result for the net profit of the company, the categories that are also not considered necessary are Quality, Employees, and Costs.

After transforming independent and dependent measurements into sets, we constructed a table truth with $2^{\mathrm{k}}$ lines, where $\mathrm{k}$ was the number of causal conditions used in the analysis. All possible conditions were not included to prevent the results from becoming insignificant and the strength and direction being unstable, considering also that a large number of conditions is also dysfunctional for QCA (Schneider \& Wagemann, 2010). In this step, the outcome is Performance and the causal conditions are the different practices and instruments of management control, namely management control practices related to Strategy, Information Systems, Performance, Employees, Quality, Costs, and Risks. Clients and Budget were not considered since they are trivial conditions. Each row in the truth table was associated with a specific combination of attributes, and the entire table thus listed all possible combinations (present or not present in the sample). Thus, it was possible to work out a combination of the existing variables to obtain high performance for net profit; that is, it was possible to propose a combination of management controls between the different categories of analysis, and it was possible to argue that these configurations were recommended 'recipes'. 
The table truth algorithm distinguished between parsimonious and intermediate solutions based on 'easy' and 'difficult' counterfactuals (Ragin, 2008). According to Fiss (2011), easy counterfactuals refer to situations in which a redundant causal condition is associated with random conditions that lead to the result in question. In contrast, 'difficult' counterfactuals refer to situations where a condition is removed from a set of causal conditions leading to a result based on the assumption that this condition is redundant.

Distinguishing between easy and difficult counterfactuals allows for the establishment of two types of solutions. The first is a parsimonious solution that includes all simplifying assumptions regardless of whether they are based on easy or difficult counterfactuals. The second is an intermediate solution that includes only simplifying assumptions based on easy counterfactuals, this being the most objective.

\subsection{Drivers of high performance}

According to the configurations, from the 45 observations that meet the minimum frequency threshold, it was possible to identify at least two combinations (Table 3). Frequency cutoff 2 is in the range of $75 \%$ to $80 \%$, as suggested by Ragin (2008). The indicated combinations exceed the consistency limit of 0.8 (consistency cutoff), which represents very high performance.

In this study, the analysis was developed based on the intermediate solution, with the variables referring to the categories of the analysis of management control practices. Combining the intermediate solution with the parsimonious one, we can identify core and peripheral conditions. The result generated two combinations of conditions settings for high performance of net income.

Table 3

\section{Settings of Conditions for High Performance of Net Income}

\begin{tabular}{lcc}
\hline Configuration & $\mathbf{1}$ & $\mathbf{2}$ \\
\hline Strategy & $\otimes$ & $\bullet$ \\
Information Systems & $\bullet$ & $\bullet$ \\
Quality & $\bullet$ & $\bullet$ \\
Performance & $\bullet$ & $\bullet$ \\
Employees & $\otimes$ & $\bullet$ \\
Risks & 0.80 & 0.846 \\
Costs & 0.102 \\
Consistency & 0.122 \\
Gross Coverage & 0.8074 \\
Single Coverage & 0.214 \\
Overall Solution Consistency & 0.092 \\
\hline General Solution Coverage & 0. \\
\end{tabular}

Black circles indicate the presence of a condition, and circles with " $\mathrm{x}$ " indicate its absence. Large circles indicate core conditions; small ones, peripheral conditions. Blank spaces indicate "don't care."

Solution 2 is the one with the greatest consistency (0.846), in which the 'recipe' is:

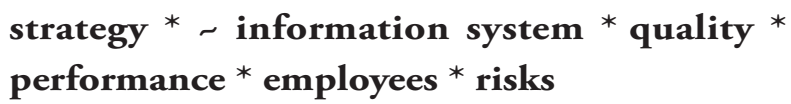

That is, to have high net profit performance management practices, it is essential to have the analytical categories Strategy, Quality, Performance, Employees, Risks, and the absence of Information System management control 
practices. This configuration reinforces Manyaeva et al.'s (2016) proposition that explains the importance of defining how strategic management data indicators are evaluated for analysis and performance control of strategy and company mission.

It is interesting to note the absence of the Information Systems management control. It should be remembered, however, that this study is working with start-ups with a very small number of stakeholders and activities, so it will not make much sense to have formal practices.

In addition to the conclusions of the study conducted by Sandino (2007), on startups investing in management controls, the author identifies four categories: information for the planning and definition of standards and the establishment of the basic operations of the company; increased operational efficiency and reduction of costs; promotion of revenue growth and customer response; and reducing risks and protecting asset integrity. Similarly, the study of Bedford et al. (2016) showed that not all observed management control practices individually associated with benefits are necessarily relevant to achieving effective results.

Solution 1 presents a consistency of 0.800 with the following 'recipe':

\section{$\sim$ strategy ${ }^{*}$ information system * performance * employees * risks * $\sim$ costs}

That is, to have high net profit performance, management practices are needed in the analysis categories Information Systems, Performance, Employees, and Risks, with the absence of Strategy and Costs.

The need for no management control for the Strategy and Costs categories is interesting. It is possible to justify this configuration since the company may be in a phase where the dynamics of the strategy are yet to be defined, and the right path is still not defined. At this point, a lot of opportunities appear, and it is more important to recognize them and take advantage of them than to be so concerned about cost. The combination no Strategy control and no Cost control is a very dangerous one, since firms could fall into a drifting situation. That is why Information Systems is key to this recipe, to avoid this situation. In this way the firm can be entrepreneurial but connected with reality. It is important to note that Budget control practices are a trivial condition, which is absolutely accepted.

The findings reinforce the study of Davila and Foster (2005), which examined hypotheses regarding the adoption of Management Accounting Systems (MAS) in start-ups. The research makes specific reference to operational budgets and another seven components of MAS: cash budgets, variance analysis, approval of operating expenses policies, investment approval policies, product and customer profitability, and acquisition costs. In the study conducted by Sandelin (2008), financial performance indicators, budgets, controlling costs, and internal controls aid the company in achieving its organizational goals.

The configurations presented with this fsQCA analysis reinforce the approach that the implementation of management controls should be considered in accordance with the stage of the start-up company's life cycle (Wang et al., 2016). This means that each company might have control mechanisms, formal or informal, adapted to its needs. However, management control practices related to Quality, Performance, Employees, and Risks are present in all recipes. This result reinforces that the use of management control tools becomes a priority for companies wishing to overcome the challenges posed by business uncertainties. In the same line of analysis, Miranda (2011) identified artefacts used for management control, covering categories related to costs, quality, performance, risks, budget, and information systems.

Erkens and Van der Stede (2015) illustrate that when causal relationships between organizational practices and organizational 
context are difficult to test using traditional quantitative methods, the fsQCA methodology can be employed as an alternative method worthy of consideration. Management control practices in start-ups may be small-scale but are necessary and systemic. The results of the study point to this tendency and the need for management controls in companies regardless of their size.

\section{Conclusion}

The purpose of this study was to examine possible combinations of categories of management control tools that lead to high performance in start-ups. The proposal was based on a specific methodological approach that was theoretically linked to the construction of the database for the identification of management control instruments and practices in nine categories of analysis within an organization. These categories are Clients, Strategy, Information Systems, Quality, Performance, Collaborators, Risks, Budget, and Costs. The methodology relied on a qualitative comparative analysis (fsQCA), an analytical technique that uses Boolean algebra to implement principles of comparison involved in qualitative studies concerning social phenomena (Rihoux \& Ragin, 2008).

Evidence was found that the management of Clients, Strategy, Information Systems, Performance, Risks, and Budgets was critical for high performance. The Clients and Budgets categories were those that presented the highest consistency: $98.98 \%$ to meet the proposed condition. The analysis was developed based on the intermediate solution, with the variables referring to the analysis categories of management control practices. The result generated two combinations of conditions for high performance regarding net income. Along these same lines, Atkinson et al. (2011) and Sandino (2007) recommend and suggest that good business management practices are required in all categories of analysis proposed in this study.

The main implication of this study is that, despite the obvious importance of management control tools, it is imperative not be too rigid. In all combinations the absence of some management control tools in some categories is critical (Information System or Strategy), meaning flexibility and space to do things differently. The study fulfilled its objectives and contributes to this area of knowledge because it identifies the management control practices that are necessary for better start-up performance, besides proposing a tool model to support incubated enterprises.

Additionally, the research findings are in line with Sandino (2007), who argues that the choice between the different categories reflects the strategy of the company, and that companies that choose management controls that are more adapted to their strategy perform better than others. The findings also align with those of the studies by Bedford et al. (2016) and Erkens and Van der Stede (2015), which aimed to identify the ideal combination of management control tools in larger organizational contexts. This study corroborates the perspective that the combination of different management control practices contributes to the success of a business, especially when related to the organization's strategy. Each company may have control mechanisms, whether formal or informal, tailored to its needs. Most decision makers will consider the high level of risk that an unknown quality of the firm and uncertain future behavior of the entrepreneur pose to a potential resource allocation in a start-up (Fritsch \& Wyrwich, 2018). This result reinforces that the use of management control tools is a priority for companies that wish to deal with the challenges posed by corporate uncertainties, especially in start-ups, thus ensuring sustainable growth for these businesses.

The main limitations of this research have to do with the sample inasmuch as this included start-ups of a single European country. This can lead to a possible bias in the interpretation of the applicability of the model to other ecosystems. For further studies, researchers are encouraged to investigate management control practices in start-ups in other countries, namely in developing countries with very different environments. At 
the same time, the funding system is likely to have a significant impact. For example, banks or venture capitalists may force some management control, distorting the start-up's behavior. Another suggestion is to replicate the study after a period of two years with the companies participating in this research and develop monitoring of the management of start-ups within different technology parks. Another important issue is related to entrepreneurial culture, flexibility, and innovation. Since too much control could have a negative effect on these, further research is needed concerning the impact of management control on innovative capacity.

\section{References}

Abernethy, M. A., \& Brownell, P. (1997). Management control systems in research and development organizations: The role of accounting, behavior and personnel controls. Accounting, Organizations and Society, 22(3), 233248. Retrieved from https://doi.org/10.1016/ S0361-3682(96)00038-4

Acs, Z. J., Brooksbank, D. J., O', C., Gorman, N. A., Pickernell, D., \& Terjesen, S. (2012). The knowledge spillover theory of entrepreneurship: An application to foreign direct investment. International Journal of Entrepreneurship and Small Business, 15(2), 237. https://doi.org/10.1504/ IJESB.2012.045206

Alvesson, M., \& Kärreman, D. (2004). Interfaces of control. Technocratic and socio-ideological control in a global management consultancy firm. Accounting, Organizations and Society, 29(3-4), 423-444. Retrieved from https://doi. org/10.1016/S0361-3682(03)00034-5

Anthony, R. N. (1965). Planning and Control Systems: A Framework for analysis (1st ed). Boston: Division of Research, Harvard Business School.

Anthony, R. N., \& Govindarajan, V. (1998). Management control systems (9th ed. 1998). Burr Ridge, Ill.: Irwin McGraw-Hill.

Atkinson, A. A., Kaplan, R. S., Matsumura, E. M., \& Young, S. M. (2011). Management accounting: Information for decision-making and strategy execution, student value edition (6th ed). EUA: Pearson.

Battisti, S. (2019). Digital social entrepreneurs as bridges in public-private partnerships. Journal of Social Entrepreneurship, In press.

Bedford, D. S., Malmi, T., \& Sandelin, M. (2016). Management control effectiveness and strategy: An empirical analysis of packages and systems. Accounting, Organizations and Society, 51(Supplement C), 12-28. Retrieved from https://doi.org/10.1016/j.aos.2016.04.002

Blank, S., \& Dorf, B. (2012). The Startup Owner's Manual: The Step-by-Step Guide for Building a Great Company. Pescadero, California: BookBaby.

Bolisani, E., \& Bratianu, C. (2017). Knowledge strategy planning: An integrated approach to manage uncertainty, turbulence, and dynamics. Journal of Knowledge Management, 21(2), 233253. Retrieved from https://doi.org/10.1108/ JKM-02-2016-0071

Bruneel, J., Ratinho, T., Clarysse, B., \& Groen, A. (2012). The evolution of business incubators: Comparing demand and supply of business incubation services across different incubator generations. Technovation, 32(2), 110-121.

Busco, C., Giovannoni, E., \& Riccaboni, A. (2017). Sustaining multiple logics within hybrid organisations: Accounting, mediation and the search for innovation. Accounting, Auditing \& Accountability Journal, 30(1), 191-216. Retrieved from https://doi.org/10.1108/AAAJ-11-2013-1520

Carraro, W. B. W. H., Battisti, S., \& Brito, C. (2019). Designing a management control model to support innovative practices in startups. International Journal of Management Practice, In press.

Chen, Q., Eriksson, T., \& Giustiniano, L. (2017). Leading well pays off: Mediating effects and multi-group analysis of strategic performance. Management Decision, 55(2), 400-412. 
Davila, A., \& Foster, G. (2005). Management accounting systems adoption decisions: Evidence and performance implications from early-stage/ startup companies. The Accounting Review, 80(4), 1039-1068. Retrieved from https://doi. org/10.2308/accr.2005.80.4.1039

Davila, A., \& Foster, G. (2007). Management control systems in early-stage startup companies. The Accounting Review, 82(4), 907-937. Retrieved from https://doi.org/10.2308/accr.2007.82.4.907

Elbashir, M. Z., Collier, P. A., \& Sutton, S. G. (2011). The role of organizational absorptive capacity in strategic use of business intelligence to support integrated management control systems. The Accounting Review, 86(1), 155-184. Retrieved from https://doi.org/10.2308/accr.00000010

Erkens, D., \& Van der Stede, W. (2015). Strategy and control: Findings from a set-theoretical analysis of high performance manufacturing firms (SSRN Scholarly Paper No. ID 2296468). Rochester, NY: Social Science Research Network. Retrieved from https://papers.ssrn.com/abstract $=2296468$

Ferreira, A., \& Otley, D. (2009). The design and use of performance management systems: An extended framework for analysis. Management Accounting Research, 20(4), 263-282. Retrieved from https://doi.org/10.1016/j.mar.2009.07.003

Fiss, P. C. (2011). Building better causal theories: A fuzzy set approach to typologies in organization research. Academy of Management Journal, 54(2), 393-420. Retrieved from https://doi. org/10.5465/AMJ.2011.60263120

Fritsch, M., \& Aamoucke, R. (2013). Regional public research, higher education, and innovative start-ups: An empirical investigation. Small Business Economics, 41(4), 865-885. https://doi. org/10.1007/s11187-013-9510-z.

Fritsch, M., \& Wyrwich, M. (2018). Regional knowledge, entrepreneurial culture, and innovative start-ups over time and space-an empirical investigation. Small Business Economics, 1-17.

Kalliath, T. J., Bluedorn, A. C., \& Gillespie, D. F. (1999). A confirmatory factor analysis of the competing values instrument. Educational and Psychological Measurement, 59, 143-158.

Lin, Y.-H., Chen, C.-J., \& Lin, B.-W. (2017). The influence of strategic control and operational control on new venture performance. Management Decision, 55(5), 1042-1064. Retrieved from https://doi.org/10.1108/MD-07-2015-0324

Magdaleno, A. M., Engiel, P., Tavares, R. L., Pisa, P. S., \& Araujo, R. M. (2017). Bridging the Gap between Brazilian Startups and business processes - Process thinking's initial exploratory case study. ISys - Revista Brasileira de Sistemas de Informação, 10(1), 19-38.

Malmi, T., \& Brown, D. A. (2008). Management control systems as a package-Opportunities, challenges and research directions. Management Accounting Research, 19(4), 287-300. Retrieved from https://doi.org/10.1016/j.mar.2008.09.003

Manyaeva, V. A., Piskunov, V. A., \& Fomin, V. P. (2016). Strategic management accounting of company costs. International Review of Management and Marketing, 6(5S), 255-264.

Mercandetti, F., Larbig, C., Tuozzo, V., \& Steiner, T. (2017). Innovation by collaboration between startups and SMEs in Switzerland. Technology Innovation Management Review, 7(12), 23-32.

Miranda, C. de S. (2011, January 11). Ensino em contabilidade gerencial: Uma análise comparativa de percepçóes de importância entre docentes $e$ profissionais, utilizando as dimensóes de atividades, artefatos e competências (text). Universidade de São Paulo. Retrieved from http://www.teses.usp. br/teses/disponiveis/12/12136/tde-04032011163936/

Nobel, C. (2011). Why companies fail-and how their founders can bounce back. Retrieved from http://hbswk.hbs.edu/item/why-companiesfailand-how-their-founders-can-bounce-back

Otley, D. (1999). Performance management: A framework for management control systems research. Management Accounting Research, 10(4), 363-382. Retrieved from https://doi. org/10.1006/mare.1999.0115 
Ragin, C. C. (1987). The comparative method: Moving beyond qualitative and quantitative strategies. Berkeley: University of California Press,.

Ragin, C. C. (2008). Redesigning social inquiry: Fuzzy sets and beyond (Vol. 240). Chicago: University of Chicago Press.

Ries, E. (2011). The lean startup: How today's entrepreneurs use continuous innovation to create radically successful businesses. Crown Publishing Group.

Rihoux, B., \& Meur, G. D. (2009). Comparative research design: Case and variable selection. In Configurational comparative methods: Qualitative comparative analysis (QCA) and related techniques. Los Angeles, London, New Delhi and Singapore: Sage.

Rihoux, B., \& Ragin, C. C. (2008). Configurational comparative methods: Qualitative comparative analysis (QCA) and Related Techniques. SAGE Publications.

Rosenthal, P. (2004). Management control as an employee resource: The case of front-line service workers. Journal of Management Studies, 41(4), 601-622.

Sánchez-Expósito, M. J., \& Naranjo-Gil, D. (2017). Effects of management control systems and cognitive orientation on misreporting: An experiment. Management Decision, 55(3), 579-594.

Sandelin, M. (2008). Operation of management control practices as a package-A case study on control system variety in a growth firm context. Management Accounting Research, 19(4), 324343. Retrieved from https://doi.org/10.1016/j. mar.2008.08.002

Sandino, T. (2007). Introducing the first management control systems: Evidence from the Retail Sector. The Accounting Review, 82(1), 265293. Retrieved from https://doi.org/10.2308/ accr.2007.82.1.265

Schneider, C. Q., \& Wagemann, C. (2010). Standards of good practice in qualitative comparative analysis (QCA) and fuzzy-sets. Comparative Sociology, 9(3), 397-418. https:// doi.org/10.1163/156913210X12493538729793

Strauß, E., \& Zecher, C. (2013). Management control systems: A review. Journal of Management Control, 23(4), 233-268. Retrieved from https:// doi.org/10.1007/s00187-012-0158-7

Trapp, M., Voigt, K.-I., \& Brem, A. (2017). Business models for corporate innovation management: Introduction of a business model innovation tool for established firms. International Journal of Innovation Management, 1850007. Retrieved from https://doi.org/10.1142/ S136391961850007X

Voss, U., \& Brettel, M. (2014). The effectiveness of management control in small firms: Perspectives from resource dependence theory. Journal of Small Business Management, 52(3), 569-587. Retrieved from https://doi.org/10.1111/jsbm.12050

Wang, Y. (2016). Environmental dynamism, trust and dynamic capabilities of family businesses. International Journal of Entrepreneurial Behavior \& Research, 22(5), 643-670. Retrieved from https:// doi.org/10.1108/IJEBR-11-2015-0234

Wang, Y., \& Ahmed, P. K. (2010). Constructing a performance measuring model for small and medium sized family businesses. International Journal of Management Practice, 4(3), 306-330.

Wang, X., Edison, H., Bajwa, S. S., Giardino, C., \& Abrahamsson, P. (2016). Key challenges in software startups across life cycle stages. In Agile Processes, in Software Engineering, and Extreme Programming (pp. 169-182). Springer, Cham. Retrieved from https://doi.org/10.1007/978-3319-33515-5_14 


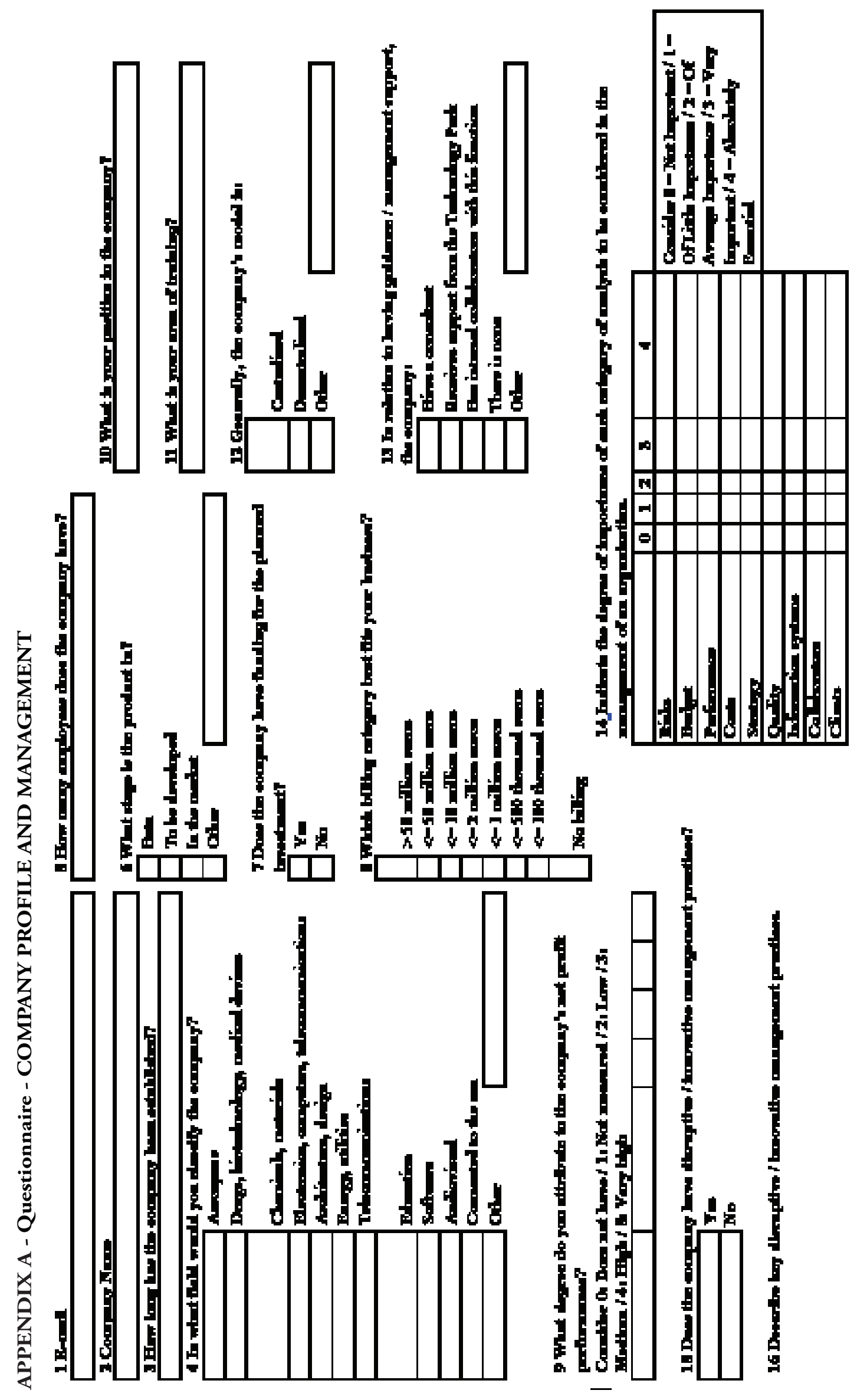


COMPANY NAME:

For the development of activities related to Management Control, some practices are indicated in the literature. Please indicate the status of use of these practices by the company.

1 - Practice fully used in the company / 2 - Practice partially used in the company / 3 - Practice possibly used in the company / 4 - Practice once used, but discontinued / 5 - Attempt to implement the practice, without success / 6 - Practice has never been used in the company

\begin{tabular}{|c|c|c|c|c|c|c|}
\hline Clients & 1 & 2 & 3 & 4 & 5 & 6 \\
\hline Customer database & & & & & & \\
\hline Customer satisfaction survey & & & & & & \\
\hline Degree of customer loyalty & & & & & & \\
\hline Customer credit policy & & & & & & \\
\hline Strategy & 1 & 2 & 3 & 4 & 5 & 6 \\
\hline 1. Business plan & & & & & & \\
\hline $\begin{array}{l}\text { 2.Declaration of purpose, mission, and } \\
\text { vision of the business }\end{array}$ & & & & & & \\
\hline $\begin{array}{l}\text { 3. Elaboration and follow-up of strategic } \\
\text { planning }\end{array}$ & & & & & & \\
\hline 4. Business model canvas & & & & & & \\
\hline Information System & 1 & 2 & 3 & 4 & 5 & 6 \\
\hline 1. Enterprise resource planning (ERP) & & & & & & \\
\hline 2. Management information systems & & & & & & \\
\hline 3. Pricing / pricing system & & & & & & \\
\hline Quality & 1 & 2 & 3 & 4 & 5 & 6 \\
\hline 1. Search for productivity improvement & & & & & & \\
\hline 2. Search for process improvement & & & & & & \\
\hline 3. Quality control systems & & & & & & \\
\hline Performance & 1 & 2 & 3 & 4 & 5 & 6 \\
\hline 2. Evaluation of the value of the company & & & & & & \\
\hline $\begin{array}{l}\text { 3. Balanced scorecard and other } \\
\text { performance evaluation instruments }\end{array}$ & & & & & & \\
\hline 4. Investment analysis / return techniques & & & & & & \\
\hline $\begin{array}{l}\text { 5. Evaluation of profitability of products } \\
\text { and customers }\end{array}$ & & & & & & \\
\hline Collaborators & & & & & & \\
\hline 1. Evaluating employee performance & & & & & & \\
\hline 2. Control over employee behavior & & & & & & \\
\hline $\begin{array}{l}\text { 3. Performance-based compensation } \\
\text { system }\end{array}$ & & & & & & \\
\hline
\end{tabular}

\begin{tabular}{|l|l|l|l|l|l|l|}
\hline Risks & 1 & 2 & 3 & 4 & 5 & 6 \\
\hline 1. Internal audits & & & & & & \\
\hline 2.Codes of business conduct & & & & & & \\
\hline 3. Loss and theft prevention control & & & & & & \\
\hline 4. Internal controls & & & & & & \\
\hline $\begin{array}{l}\text { 5. Credit and collection - credit and } \\
\text { collection decisions and controls }\end{array}$ & & & & & & \\
\hline 6. Stock management & & & & & & \\
\hline 7. Capital expenditure approval policies & & & & & & \\
\hline 8. Policies for approving operating expenses & & & & & & \\
\hline Budget & 1 & 2 & 3 & 4 & 5 & 6 \\
\hline 1.Control for investment in long-term assets & & & & & & \\
\hline 2. Elaboration and control of the capital budget & & & & & & \\
\hline $\begin{array}{l}\text { 3. Elaboration and control of the } \\
\text { operational budget }\end{array}$ & & & & & & \\
\hline 4. Elaboration and control of cash flow & & & & & & \\
\hline 5.Payment planning & & & & & & \\
\hline Costs & 1 & 2 & 3 & 4 & 5 & 6 \\
\hline 1. Break-even analysis - cost profit volume & & & & & & \\
\hline 2. Analysis of costs and expenses & & & & & & \\
\hline 3. Determination of costs of products / services & & & & & & \\
\hline
\end{tabular}


About the Authors:

1.Wendy Beatriz Witt Haddad Carraro, PhD in Entrepreneurship and Innovation, University of Porto, Faculty of Economics, Porto, Portugal. E-mail: wendy.carraro@ufrgs.br

ORCID

(iD) 0000-0002-2152-1767

2.Raquel Meneses, PhD in Management Sciences, University of Porto, Faculty of Economics, Porto, Portugal. E-mail: raquelm@fep.up.pt

ORCID

(iD) 0000-0001-5829-9402

3.Carlos Brito, PhD in Marketing, University of Porto, Faculty of Economics, Porto, Portugal.

E-mail: cbrito@fep.up.pt

ORCID

(iD) 0000-0003-0307-9220

\section{Contribution of each author}

\begin{tabular}{|c|c|c|c|}
\hline Contribution & Wendy Carraro & Raquel Meneses & Carlos Brito \\
\hline 1. Definition of research problem & $\sqrt{ }$ & $\sqrt{ }$ & $\sqrt{ }$ \\
\hline 2. Development of hypotheses or research questions (empirical studies) & $\sqrt{ }$ & $\sqrt{ }$ & $\sqrt{ }$ \\
\hline \multicolumn{4}{|l|}{ 3. Development of theoretical propositions (theoretical Work) } \\
\hline 4. Theoretical foundation/ Literature review & $\sqrt{ }$ & & \\
\hline 5. Definition of methodological procedures & $\sqrt{ }$ & $\sqrt{ }$ & \\
\hline 6. Data collection & $\sqrt{ }$ & & $\sqrt{ }$ \\
\hline 7. Statistical analysis & $\sqrt{ }$ & $\sqrt{ }$ & \\
\hline 8. Analysis and interpretation of data & $\sqrt{ }$ & $\sqrt{ }$ & $\sqrt{ }$ \\
\hline 9. Critical revision of the manuscript & $\sqrt{ }$ & $\sqrt{ }$ & $\sqrt{ }$ \\
\hline 10. Manuscript Writing & $\sqrt{ }$ & $\sqrt{ }$ & $\sqrt{ }$ \\
\hline 11. Other (please specify which) & & & \\
\hline
\end{tabular}

\section{Erratum}

Where was written:

"Review of Business Management, São Paulo, v.21, n.5, p.861-878, oct/dec. 2019."

Now read:

“Rev. Bras. Gest. Neg. São Paulo v.21 n.4 oct-dec. 2019 p. 861-878” 